\title{
Exercise Behaviour in Patients with Chronic Diseases
}

\author{
S Wright ${ }^{1}, \mathrm{C}_{\text {Gordon }}{ }^{1}, \mathrm{MG}$ Lee $^{2}$
}

\begin{abstract}
Objective: This study was aimed at identifying the stages of exercise behaviour changes experienced by patients with chronic illnesses and the relationship with their exercise self-efficacy. Method: The patients attending the Medical clinics at the University Hospital of the West Indies (UHWI), Jamaica, with chronic illnesses were studied. The data were collected using three questionnaires.

Result: There were 75 females and 25 males. Fifty-one per cent of the patients were in the contemplation stage of exercise behaviour changes and $29 \%$ in the maintenance stage. The majority (61\%) were non-adopters and $39 \%$ were adopters (action and maintenance) with $37 \%$ of the females adopters compared to 44\% of the males. The mean self-efficacy scores of subjects in stages four and five were significantly higher than those in stage two (contemplation). The highest level of adopters was in the 18 to 30-year age group. In the patients with one chronic condition, there were 55\% non-adapters among the patients with one chronic condition compared to $71 \%$ of those with more than one condition.

Conclusion: Most patients with chronic disorders were in the contemplation stage and their self-efficacy scores were greater for those in the action and maintenance stages. Health practitioners need to increase the efforts to encourage physical activities particularly in the earlystages of behaviour changes.
\end{abstract}

Keywords: Chronic disease, exercise, health behaviour

\section{El Comportamiento con Respecto al Ejercicio en Pacientes con Enfermedades Crónicas \\ S Wright ${ }^{1}$, C Gordon 1 , MG Lee ${ }^{2}$}

\begin{abstract}
RESUMEN
Objetivo: Este estudio tuvo como objetivo identificar las etapas de los cambios de comportamiento experimentados por los pacientes con enfermedades crónicas en relación con los ejercicios, y la relación con su autoeficacia al realizarlos.

Método: Se estudiaron los pacientes con enfermedades crónicas, que asisten a las Clínicas Médicas en el Hospital Universitario de West Indies (HUWI), Jamaica. Los datos se recogieron mediante tres cuestionarios.

Resultado: Hubo 75 mujeres y 25 hombres. El cincuenta y uno por ciento de los pacientes estaban en la etapa de contemplación de cambios de comportamiento con respecto al ejercicio, mientras que el 29\% se hallaban en la etapa de mantenimiento. La mayoría (61\%) eran no adoptadores y el 39\% eran adoptadores (acción y mantenimiento), siendo el 37\% de las mujeres adoptadoras en comparación con el $44 \%$ de los hombres. Las puntuaciones medias de la autoeficacia de los sujetos en las etapas cuatro y cinco, fueron significativamente superiores a los de la etapa dos (contemplación). El nivel más alto de adoptadores fue el del grupo de 18 a 30
\end{abstract}

From: ${ }^{1}$ School of Physical Therapy and ${ }^{2}$ Department of Medicine, The University of the West Indies, Kingston 7, Jamaica, West Indies.
Correspondence: Professor MG Lee, Department of Medicine, The University of the West Indies, Kingston 7, Jamaica, West Indies. Email: michael.lee@uwimona.edu.jm 
años de edad. En los pacientes con una condición crónica, hubo un 55\% de no adoptadores entre los pacientes con una condición crónica, en comparación con el $71 \%$ de las personas con más de una condición.

Conclusión: La mayoría de los pacientes con trastornos crónicos estaban en la etapa de contemplación, y sus puntuaciones de autoeficacia fueron mayores para aquellos en las etapas de acción y mantenimiento. Los profesionales de la salud deben aumentar los esfuerzos para fomentar las actividades fisicas, especialmente en las primeras etapas de cambios de comportamiento.

Palabras claves: Enfermedad crónica, ejercicio, comportamiento de salud

West Indian Med J 2017; 66 (2): 341

\section{INTRODUCTION}

Regular physical activities are important in the maintenance of people's physical as well as psychological wellbeing. This is particularly important for individuals with chronic illnesses (1). Lifestyle factors such as physical in activities are correlated with the development of many chronic diseases (2). In fact, physical activities and exercise are now considered the principal interventions for use in primary and secondary prevention of chronic diseases especially with the high prevalence of these disorders (3). Despite these, most populations find it difficult to begin and maintain any form of exercise routine. To promote and maintain human health, all healthy adults aged 18 to 65 years need moderate-intensity aerobic physical activities for a minimum of 30 minutes on five days weekly or vigorous-intensity aerobic physical activities for a minimum of 20 minutes on three days each week $(4,5)$. In recent decades, technology and economic incentives have combined to discourage physical activity as technology reduces the amount of energy needed to carry out many activities of daily living and the economy offers more remuneration for sedentary work as opposed to that done actively (5).

Healthcare professionals have innovated new ways of promoting physical fitness, including the development of exercise interventions based on the theories of behaviour change, such as the transtheoretical model [TTM] (6). In order to increase physical activity levels, TTM has been applied to the acquisition of and adherence to exercise behaviours with success (7). The TTM postulates that health behaviour changes involve progress through six stages of change: pre-contemplation, contemplation, preparation, action, maintenance and termination. As a rule of thumb, at-risk populations are predicted to be $40 \%$ in the pre-contemplation, $40 \%$ in the contemplation and $20 \%$ in the preparation stage (8).

Self-efficacy is one of the major theories forming the core of the transtheoretical model. As described by
Fallon and Hausenblas, self-efficacy refers to the situation specific confidence that a person can cope with highrisk situations and not relapse to the problem behaviour (6). Self-efficacy is necessary for individuals to move through the stages of change (9).

Jamaica, like other countries may have similar problems regarding exercise which is compounded by a growing percentage of the population that struggles with chronic illnesses and physical inactivity. A major challenge faced, however, is the non-compliance with the recommendations to initiate and maintain physical activities and exercise as a way of life. Therefore, it is important to identify the hindrances faced by patients and to increase the knowledge of how patients experience the implementation of exercise, in order to identify the motivators and barriers. This can be used to create clinical strategies that encourage and support the initiation and maintenance of regular exercise among patients with chronic illnesses (10). The present study seeks to identify the stages of exercise behaviour changes that are experienced by individuals suffering from chronic illnesses and the relationship of these stages with exercise self-efficacy.

\section{SUBJECTS AND METHODS}

A non-experimental cross-sectional design was used to meet the objectives of this study. Approval for the study was obtained from the Ethics Committee of the University Hospital of the West Indies/The University of the West Indies/Faculty of Medical Sciences, Mona.

The patients attending the medical clinics at the UHWI, Mona, Jamaica, who were suffering from chronic illnesses constituted the available population eligible for inclusion in the study. The inclusion criteria for the study were: patients who had been diagnosed with one or more chronic illnesses within the last ten years and age 18 years old or older. The target population consisted of individuals suffering from chronic illnesses; including di- 
abetes, hypertension, renal failure, chronic cardiac conditions and cancer.

Consecutive patients attending the clinics who met the criteria were asked to participate in the study. Upon their agreement, an informed signed consent was obtained. The data were obtained with three questionnaires, interview was administered by research assistants. Each interview lasted approximately 15 minutes. A total of 100 subjects were recruited.

The questionnaire was a clinical and demographic one which included age, gender, type of chronic condition and the number of chronic conditions, an exercise self-efficacy scale and a stage of behavioural change questionnaire (11). The exercise self-efficacy scale consisted of 18 questions related to the participants' level of confidence to exercise when other things get in their way. The responses were given on a scale of one (not at all confident) to five (completely confident). The levels of self-efficacy were determined by adding the scores given for each item. Higher scores indicated greater self-efficacy. This scale has alpha values ranging from 0.773 to 0.869 indicating its reliability and validity. The continuous measure of the stages of exercise change consisted of 24 questions. The subjects were asked to respond to the questions on a scale of one (strongly disagree) to five (strongly agree). This measure has alpha values as high as 0.939 . Its validity has been previously tested and hence, provides representative values of the variables being assessed at the various stages. All the items representing pre-contemplation, contemplation, preparation, action and maintenance were grouped accordingly. The responses given for each item were summed and the subjects put into the stage for which they received the highest scores.

To compare self-efficacy scores across the stages of change, the five stages were compressed into two, namely adopters (action/maintenance) and non-adopters. (pre-contemplation/contemplation/preparation) of exercise behaviour.

\section{Data analyses}

The data were analysed using the Statistical Package for the Social Sciences (SPSS) tool. The percentage of the subjects in each stage of exercise behaviour change was calculated. The relationship between the subjects' selfefficacy and their stages of exercise behaviour change was determined using the one-way Analysis of variance (ANOVA). An alpha level of 0.05 was used for statistical significance. Chi-square was used to determine the relationship between age, gender, number of chronic con- ditions ( 1 or $>1)$ and the stages of change compounded (adopter or non-adopter). The stages were compressed to increase the number of the subjects in each category for the use of the Chi-square statistics.

\section{RESULTS}

A total of 100 subjects were included in the study, $75 \mathrm{fe}-$ males and 25 males. Fifty-one per cent of the subjects were in the contemplation stage of exercise behaviour change and $29 \%$ in the maintenance stage. The action, pre-contemplation and preparation stages accounted for $10 \%, 5 \%$ and $5 \%$, respectively.

The mean self-efficacy scores of the subjects in stages four (action) and five (maintenance) were significantly higher than those in stage two [contemplation] ( $p$ $=0.037$ and $p<0.001$, respectively). Those in stages four and five had mean self-efficacy scores of 61 and 62 , respectively, while those in stage two had a mean score of 44.

When the five stages were compressed into two stages, non-adopters and adopters, most of the subjects (61\%) were non-adopters. The remaining 39\% were in the adopter stage.

In comparing their mean self-efficacy scores with the stages of exercise behaviour change, the adopters had consistently higher self-efficacy scores than the nonadopters (Fig. 1).

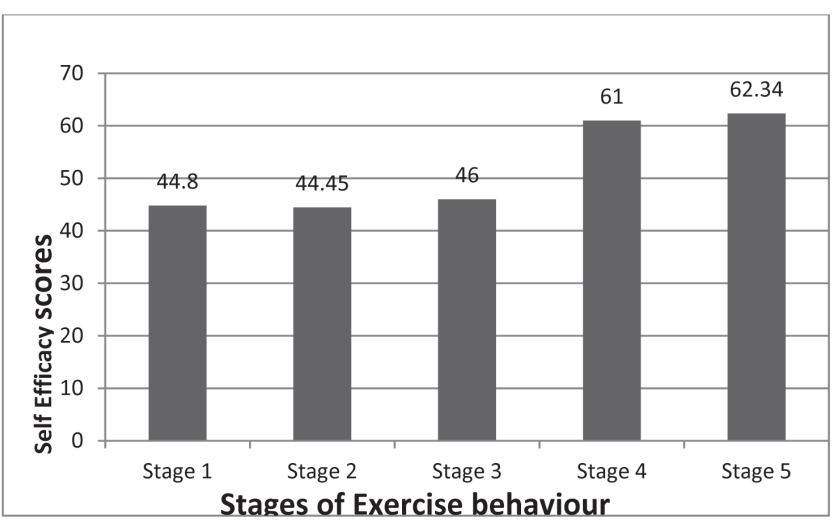

Fig. 1: Stages of exercise behaviour change and the related self-efficacy scores

Stages: 1 - pre-contemplation, 2 - contemplation, 3 - preparation, 4 - action, 5 - maintenance

The relationship between the subjects' gender and their stage of the exercise behaviour change revealed that $37 \%$ of the females were adopters compared to $44 \%$ of the males and $63 \%$ of the females were non-adopters as compared to $56 \%$ of the males $[p>0.05$, Table 1$]$. 
Table 1: Gender and the stages of exercise behaviour change

\begin{tabular}{lccc}
\hline Gender & Non-adopters & Adopters & Total \\
\hline Female & $47(63 \%)$ & $28(37 \%)$ & $75(100 \%)$ \\
Male & $14(56 \%)$ & $11(44 \%)$ & $25(100 \%)$ \\
\hline
\end{tabular}

$p=0.638$

The highest level of adopters was found to be in the 18 to 30 -year-old age group, $50 \%$ as compared to $39 \%$ in the 31 to 50 -year-old age group, $40 \%$ for the 51 to 65 year-old age group and $25 \%$ in the over 65 -year-old age group $(p>0.05)$ [Table 2].

Table 2: Age groups and stage of exercise behaviour change

\begin{tabular}{ccrc}
\hline Age group & Non-adopters & Adopters & \multicolumn{1}{c}{ Total } \\
\hline $18-30$ & $5(50 \%)$ & $5(50 \%)$ & $10(100 \%)$ \\
$31-50$ & $17(61 \%)$ & $11(39 \%)$ & $28(100 \%)$ \\
$51-65$ & $30(60 \%)$ & $20(40 \%)$ & $50(100 \%)$ \\
Over 65 & $9(75 \%)$ & $3(25 \%)$ & $12(100 \%)$ \\
\hline
\end{tabular}

$p=0.678$

The number of chronic conditions patients had, influenced their readiness to exercise. In patients with one chronic condition, $55 \%$ were non-adopters compared to $71 \%$ of those who had more than one chronic condition. On the other hand, $45 \%$ of the subjects with one chronic condition were adopters compared to $28 \%$ who had more than one chronic condition.

\section{DISCUSSION}

Lifestyle factors, especially physical inactivity, are correlated with the development of many chronic diseases and physical activities and exercise are considered one of the principal interventions for use in primary and secondary prevention of chronic diseases (1). Conditions such as cardiovascular disease, Type II diabetes mellitus, obesity and cancer are improved when physical activities and exercise are part of a medical management plan $(3,12)$. Although regular exercise is important for patients with coronary artery disease (CAD), most CAD patients are not sufficiently active (13). Regular physical exercise by patients on dialysis significantly reduces their cardiovascular risk factors. It improves their physical capacity and psychological well-being (10). The results of the present study showed that most of the subjects were non-adopters, which may indicate that most patients with chronic diseases are not carrying out the required level of physical activities despite the benefits of physical activities and exercise to their conditions. A possible explanation for this may be that they are not aware of the relevance of exercise in the maintenance of their health as well as in the prevention of other related conditions. Also, it is possible that these patients may experience various barriers such as the unavailability of time and a lack of interest and motivation to exercise (10). In a prior report, it was found that more than 60 per cent of American adults was not regularly physically active and 25 per cent of all adults were not active at all (14). In fact, over $40 \%$ of Americans are sedentary and $51 \%$ of Canadians were inactive $(2,7)$.

The TTM recommends the use of the following constructs to move between the stages: self-efficacy, temptation, decisional balance and the processes of change. Self-efficacy is the situation-specific confidence of an individual to overcome a high-risk circumstance without a relapse into an unhealthy habit (7). In fact, self-efficacy is the belief and conviction that one can successfully perform a given activity (15). Meta-analyses have shown that self-efficacy for exercise increases with each stage of change, but does so in a non-linear pattern (7). Exercise self-efficacy is an important predictor of the adoption and maintenance of exercise behaviours. Patients' compliance with exercise prescriptions is more likely to be successful if their exercise self-efficacy is assessed and enhanced (15). In the present study, the selfefficacy scores of patients in the non-adopter stages were lower than those in the adopter stages, also, a significantly higher score was found for the self-efficacy of patients in stages five and four as compared to those in stage two. The reason for such high self-efficacy values within the adopters' category may be due to the fact that, confidence as well as high levels of self-efficacy are important for the commencement as well as the maintenance of exercise, as personal drive and self-motivation have to be sufficient to eliminate all doubts of terminus behaviour when barriers are presented. Physicians and other healthcare professionals should therefore help all patients to increase their self-efficacy.

The self-efficacy scores of men in this study were significantly higher than those of the women. Likewise, more men were found to be in higher stages of exercise behaviour change than women, implying that the males were more physically active than the females, these findings are consistent with that of a recent United States of America report (14). In another study, exercise maintainers were significantly more likely to be males, to have 
an exercise history, less likely to perceive exercise barriers and to be current or past smokers (16). A likely explanation is that men had higher self-efficacy values as well as increased self-motivation. Additionally, males have a greater physiological capacity to perform more demanding physical activities. Socially, it may be expected that men exert more physical prowess in their communities which may help to maintain their level of fitness and strength.

Although exercise and physical activities are considered the principal interventions for primary and secondary disease prevention, physical inactivity is escalating in all age groups around the world (3). Physical inactivity is a modifiable risk factor for an increasing number of chronic diseases (2). A previous report concluded that people in the older age groups were more physically active (17). However, in this study, the youngest age group of 18 to 30 years had the most adopters to exercise behaviour changes. This was followed by the 51 to 65 and 31 to 50 age groups. The increase in the activity levels of the younger population may be attributed to the increased awareness of the importance of physical activities and the greater engagement of the young with the media by which these health behaviour changes are promoted. In a study in older persons, their stage of change did not predict their exercise adoption, but their baseline self-efficacy predicted their walking behaviours. These results lend partial support to the TTM in predicting exercise behaviours (18).

Individuals with chronic diseases are likely to become less physically active and this may be exacerbated by the presence of multiple diseases. The result of this may be a loss of their functional capacity and subsequent further reductions in their ability to perform exercise (3). In the present study, when comparing the number of chronic conditions to the stage of exercise behaviour changes, it was found that the majority of the nonadopters were among the patients with more than one chronic condition. The results may suggest that having more than one chronic condition presents an individual with additional barriers to exercise causing non-adoption of exercise behaviour changes. The lack of awareness and knowledge about the recognized risk factors may have influence on an individual's risk perception (1). A low percentage of adults identified a lack of physical activities as a risk factor for their diseases. This view is supported by a low knowledge of the influence of lifestyle on people's health problems even among well educated people (1).
There were limitations in the present study. The total number of the subjects studied was relatively small and this may have reduced the power of the study. The questionnaire administration method may be biased as patients might give answers to interviewers which they perceived to be correct.

In conclusion, most of the patients with chronic conditions were found in the contemplation stage of exercise behaviour change and the self-efficacy scores of the patients in the action and maintenance stages were greater than those in the previous three stages. More men than women, were involved in regular physical activities. The subjects between the ages of 18 and 30 years of age were more active than older subjects and the number of chronic conditions influenced their stages of exercise behaviour change. It is therefore important that health practitioners increase their efforts to encourage the initiation of physical activities particularly for those people in the early-stages of their behavioural changes.

\section{REFERENCES}

1. Kruk J. Physical activity in the prevention of the most frequent chronic diseases: an analysis of the recent evidence. Asian Pacific J Cancer Prev2007; 8: 325-38.

2. Warburton DER, Nicol CW, Bredin SSD. Health benefits of physical activity: the evidence. Can Med Assoc J 2006; 174: 8019.

3. Durstine JL, Gordon B, Wang Z, Luo X. Chronic disease and the link to physical activity. J Sport Health Sci 2013; 2: 3-11.

4. Blair SN, LaMonte MJ, Nichaman MZ. The evolution of physical activity recommendations: how much is enough? Am J Clin Nutr 2004; 79: 913S-920S.

5. Haskell W, Thompson P, Heath G, Macera C, Franklin B, Blair S et al. Physical activity and public health: updated recommendation for adults from the American College of Sports Medicine and the American Heart Association. Med Sci Sports Exer 2007; 39: 1423-34.

6. Fallon E, Hausenblas H. Transtheoretical model: Is termination applicable to exercise? Amer J Health Studies 2004; 19: 35-44.

7. Fallon EA, Hausenblasb HA, Nigg CR. The transtheoretical model and exercise adherence: examining construct associations in later stages of change. Psychol Sport Exercise 2005; 6: 62941.

8. Prochaska JO, Velicer WF. The transtheoretical model of health behavior change. Am J Health Promot 1997; 12: 38-48.

9. Lenio J. Analysis of the transtheoretical model of behaviour change. J Student Res 2006; $5^{\text {th }}$ Edition: 73-86.

10. Heiwe S, Tollin H. Patients' perspectives on the implementation of intra-dialytic cycling - a phenomenographic study. Implement Sci 2012; 7: 68. doi:10.1186/1748-5908-7-68PMCID: PMC 3444901

11. Marcus BH, Selby VC, Niaura RS, Rossi JS. Self-efficacy and stages of exercise behaviour change. Research Quaterly for Exercise and Sport 1992; 63: 60-6.

12. Taylor RS, Brown A, Ebrahim S, Jolliffe J, Noorani H, Rees K et al. Exercise-based rehabilitation for patients with coronary heart 
disease: systematic review and meta-analysis of randomized controlled trials. Am J Med 2004; 116: 682-92.

13. Kanning M. Physically active patients with coronary artery disease: A longitudinal investigation of the processes of exercise behaviour change. Br J of Health Psychol 2010; 15: 583-97.

14. US Department of Health and Human Services. Physical activity and health: a report of the surgeon general. Atlanta, GA: US Department of Health and Human Services, Centers for Disease Control and Prevention, National Center for Chronic Disease Prevention and Health Promotion, 1996.

15. Fletcher JS, Banasik JL. Exercise self-efficacy. Clin Excell Nurse Pract 2001; 5: 134-43.
16. Leung YW, Ceccato N, Stewart DE, Grace SL. A prospective examination of patterns and correlates of exercise maintenance in coronary artery disease patients. J Behav Med 2007; 30: 41121.doi:10.1007/s10865-007-9117-4.

17. Yates BC, Price-Fowlkes T, Agrawal S. Barriers and facilitators of self-reported physical activity in cardiac patients. Res Nurs Health 2003; 26: 459-69.

18. Cheung C, Wyman J, Gross C, Peters J, Findorff M, Stock H. Exercise behavior in older adults: a test of the transtheoretical model. J Aging Phys Act 2007; 15: 103-18. 